\title{
Testes de Atenção Dividida Alternada
}

\author{
Juliana Oliveira Gomes ${ }^{1}$ - Universidade São Francisco, Itatiba, Brasil
}

Rueda, F. M. (2010). Teste de Atenção Dividida (TEADI) e Teste de Atenção Alternada (TEALT). São Paulo: Casa do Psicólogo.

Fabián Javier Marín Rueda é psicólogo, perito em avaliação psicológica pela Universidade de Ribeirão Preto; mestre e doutor em Avaliação Psicológica pelo Programa de Pós-Graduação Stricto Sensu em Psicologia da Universidade São Francisco. Por meio da publicação da obra, o autor pretendeu fornecer instrumentos de medida da atenção, construídos e direcionados para o contexto do trânsito.

O manual do Teste de Atenção Dividida (TEADI) e Teste de Atenção Alternada (TEALT) é dividido de maneira que a primeira parte se dedica à fundamentação teórica sobre a atenção e psicologia do trânsito, seguido dos estudos psicométricos de cada um dos testes, individualmente. Por último são apresentadas as normas de aplicação, material necessário e instruções de correção e interpretação.

De maneira geral, a atenção pode ser entendida como um processo utilizado para o alcance de tarefas ou realização de certos objetivos, no qual os estímulos úteis são selecionados para serem utilizados, enquanto os demais são ignorados. Já em 1890, William James a definiu como a tomada de uma informação pela mente em detrimento de vários estímulos simultâneos ou séries de pensamentos e, embora ao longo dos anos tenham sido apresentadas diferentes definições para tal construto, recorrentemente este conceito apresentado por James é referenciado.

A atenção foi inicialmente conceituada como um fenômeno ativo de processamento, a qual utilizaria os órgãos dos sentidos a fim de identificar informações, memórias e outros processos cognitivos necessários para a realização de tarefas. Ela também já foi indicada como um processo de facilitação, partindo do pressuposto que um mecanismo cerebral era o responsável pela seleção e omissão de estímulos.

Ao longo dos anos foram construídos diferentes modelos explicativos para o processo atentivo. Dessa forma, foram criadas diversas terminologias para defini-lo, o que gerou uma falta de consenso sobre sua conceituação. Por essa razão, a construção de instrumentos de medidas com uma definição clara do construto se faz importante no sentido de uma avaliação válida e fidedigna do mesmo.

Para os estudos de construção dos referidos testes, o autor se centrou nos conceitos de atenção

${ }^{1}$ E-mail: juogomes-usf@yahoo.com.br dividida relacionada à possibilidade da pessoa de manter sua atenção em estímulos diferentes para executar uma ou mais tarefas distintas simultaneamente; e de atenção alternada, relativa à capacidade de se alternar o foco atencional entre um estímulo e outro na execução de uma tarefa. Assim sendo, para a avaliação da atenção dividida, solicita-se ao indivíduo que ele mantenha seu foco em pelo menos dois estímulos-alvo, num exercício, enquanto na tarefa de atenção alternada, requisita-se que seja procurado ora um alvo, ora outro, alternadamente.

Dando sequência ao manual, o autor apresenta estudos que tangem à avaliação da atenção especificamente relativa à condução de veículos automotores, de forma a concluir sua fundamentação teórica sobre atenção ao mesmo tempo em que inicia uma discussão sobre a psicologia do trânsito. $\mathrm{Na}$ verdade, os estudos desenvolvidos no Brasil sobre este contexto se centram na procura por evidências de validade para os instrumentos, uma vez que a avaliação psicológica é requisito tradicional para obtenção da carteira de habilitação. No entanto, questões mais específicas, como, por exemplo, o envolvimento ou não da atenção em acidentes de trânsito, não são demonstradas empiricamente.

Por essa razão, o autor se vale de um breve levantamento histórico da psicologia do trânsito a fim de apresentá-la, desde sua origem, na década de 1950, até a formulação do Conselho Nacional de Trânsito, o qual tornou obrigatório o exame psicotécnico para os candidatos à Carteira Nacional de Habilitação (CNH), posteriormente denominado de avaliação psicológica pericial. A discussão sobre quais aspectos devem ser analisados nessa avaliação pericial levou ao questionamento de quais tipos de atenção deveriam ser verificados para obtenção da carteira de motorista. Assim, pensando na ausência de instrumentos de medida para aferição de alguns dos tipos de atenção, a criação de testes com essa finalidade se fez necessária, o que justifica a construção dos Testes de Atenção Dividida (TEADI) e Alternada (TEALT).

Baseando-se, então, em sua fundamentação teórica, dando continuidade ao manual, o autor apresentou os estudos psicométricos para os testes, separadamente. O TEADI mede a capacidade do indivíduo de dividir a atenção. Tal medida é baseada nos estímulos que deveriam ser marcados e que foram 
assinalados devidamente, subtraindo-se os erros e omissões, ou seja, estímulos distratores que não deveriam ser assinalados, mas o foram, e estímulosalvo que não foram marcados. No total, o teste se apresenta com 450 estímulos, distribuídos em 30 linhas. O tempo médio de aplicação é de 5 minutos.

O TEALT, por sua vez, mede a capacidade de se alternar a atenção. O resultado é calculado com base nos estímulos corretamente marcados, subtraindo-se os erros e omissões, ou seja, estímulos distratores marcados indevidamente e estímulos alto deixados em branco. O teste é composto por 352 estímulos distribuídos em 16 linhas, requisitando-se que para cada linha do teste a pessoa procure um estímulo diferente da seguinte. O tempo total de realização é de 2 minutos e 30 segundos.

Os estudos psicométricos, tanto do TEADI quanto do TEALT, foram realizados com pessoas do estado da Bahia e Sergipe, candidatos à obtenção, renovação, mudança ou adição de categoria na $\mathrm{CNH}$. Foram encontradas evidências de validade de construto pela diferenciação das idades e evidências de validade de critério em relação à escolaridade, com os testes de
Atenção Dividida e Sustentada, de Atenção Concentrada (TEACO-FF) e com o Teste Não-Verbal de Inteligência. Para o TEADI foram também encontradas evidências de validade de critério com o Teste de Atenção Concentrada (AC) e para o TEALT, com o Teste Conciso de Raciocínio (TCR). Para ambos foram também descritos estudos de precisão, estudada pelo alfa de Cronbach e pelo método das duas metades de Guttman e Spearman-Brown.

Por fim, são apresentadas para ambos os testes, separadamente, as normas de aplicação, população-alvo, material necessário, instruções, normas de correção e interpretação gerais e divididas por estado. Ao final, foram anexados exemplos de protocolos avaliados. Ambos os testes podem ser aplicados individual ou coletivamente, e as instruções para aplicação, correção e interpretação devem ser seguidas com rigor, a partir do apresentado no manual.

Com base no exposto, pode-se dizer que o TEADI e o TEALT representam bons instrumentos para a avaliação da atenção dividida e alternada em motoristas.

Sobre a autora:

Juliana Oliveira Gomes é psicóloga, formada pela Universidade Federal de Juiz de Fora (2007), mestre em Psicologia pela Universidade São Francisco (2009) e discente do curso de Pós-Graduação Stricto Sensu, Doutorado em Psicologia na mesma Universidade. 